\title{
Acquisition age of lateral and rhotic phonemes: the opinion of Speech and Language Therapists from Santiago, Chile
}

\author{
Daniela Paz Rojas Contreras ${ }^{1}$ \\ https://orcid.org/0000-0002-3954-8327 \\ María Angélica Fernández Gallardo ${ }^{1}$ \\ https://orcid.org/0000-0002-0045-3048 \\ Christian Iván Peñaloza Castillo' \\ https://orcid.org/0000-0001-9437-0296 \\ Felipe Hernán Torres Morales ${ }^{1}$ \\ https://orcid.org/0000-0001-7673-317X \\ Josué David Pino Castillo' \\ https://orcid.org/0000-0003-2412-2718 \\ Mario Andrés Bustos Rubilar ${ }^{1}$ \\ https://orcid.org/0000-0002-0796-0202 \\ Patricia Bernardita Castro Abarca ${ }^{1}$ \\ https://orcid.org/0000-0002-1372-9920 \\ Eduardo Andrés Fuentes-López ${ }^{2}$ \\ https://orcid.org/0000-0002-0141-0226
}

Universidad de Chile, Departamento de Fonoaudiología, Santiago, Chile.

Pontificia Universidad Católica de Chile, Facultad de Medicina, Departamento de Ciencias de la Salud, Carrera de Fonoaudiología, Santiago, Chile.

Conflict of interests: Nonexistent

\section{(c) (i)}

Received on: August 28, 2018 Accepted on: December 20, 2018

Corresponding address: Daniela Paz Rojas Contreras Avenida Independencia 1027, Independencia

Codigo Postal: 8380453

Santiago, Chile

E-mail: drojasc@med.uchile.cl

\section{ABSTRACT}

Purpose: to describe at which age do speech and language therapists consider the $/ \mathrm{l} /, / \mathrm{r} /, / \mathrm{r} /$ phonemes should be acquired; to describe the criteria used by speech and language therapists to consider a phoneme as acquired; and to investigate the diagnostic criteria used by these professionals.

Methods: this is an analytical cross-sectional study in which an online questionnaire was completed by 151 speech and language therapists from the Metropolitan region of Chile. The questionnaire included questions regarding the aims of this study.

Results: around a $30 \%$ of respondents considered the $/ / /$ phoneme to be acquired between 3,6-4,6 years, a $72 \%$ agreed on the /r/ phoneme to be acquired from 4,0 to 4,11 and a $40 \%$ declared the acquisition of the $/ r /$ phoneme between $5,6-5,11$. When determining a phoneme as acquired, a $46.3 \%$ of interviewees referred to do it only when it was produced always and a $30 \%$ declared to consider as such when produced more than $50 \%$ of the times. When exposed to a real case, respondents provided three different diagnostic options.

Conclusion: results showed a wide age range in which speech and language therapists consider the lateral and rhotic phonemes to be acquired, showing no consensus. There are diverse criteria to determine when each phoneme is acquired. Similarly, different opinions were evidenced regarding when a disorder would be defined as phonologic or articulatory.

Keywords: Speech, Language and Hearing Sciences; Articulation Disorders; Expert Testimony; Phonetics 


\section{INTRODUCTION}

In the Speech and Language Therapy practice with children, it is important to have referential acquisition ages of phonemes for the diagnosis and intervention of speech and/or language difficulties. However, when investigating the literature different criteria are used to determine when and how this acquisition is achieved, hence the referential ages vary ${ }^{1-7}$.

For example, Vivar and León $(2009)^{5}$ determined in a group of Chilean children that the phoneme / I / was present in $90 \%$ of the 3.6 to 3.11 years old group, the $/ \mathrm{r} /$ was present in the same percentage between 4 and 4.5 and finally the $/ \mathrm{r} /$ was present only $80 \%$ of the time, in children between 5.5 and 5.11 years. In contrast, in a study conducted in Mexico, Melgar (2007) ${ }^{4}$ determined that $90 \%$ of children between 3.0 and 3.5 years old had acquired the phoneme / I /; same percentage was observed for the group between 4.0 and 4.5 years with the phoneme / r / and the group between 6.0 and 6.5 years for the the phoneme $/ \mathrm{r} /$. The analysis carried out by Vivar and León is based on the percentage of appearance of the phoneme, however Melgar based it on a percentage of children in the sample. This last criterion was also used by Bermeosolo (2001) ${ }^{1}$, who obtained as a result that the phoneme / 1 / is in $90 \%$ of the sample of children between 3.0 and 4.11 years and in $100 \%$ at 5.0 years old. The $/ \mathrm{r} /$ is found in $80 \%$ of the group between 3.0 and 3.11 years and in 100\% from the age of 4 years. As for the multiple vibrant phoneme, between 3.0 and 3.11 years it would be present in $50 \%$ of the sample, in $70 \%$ between 4.0 and 5.11 years, $80 \%$ from 6.0 to 6.11 and $90 \%$ between 7.0 and 7.11 years. The information is delivered without differentiating the context in which the phoneme appears (onset or coda).

Considering the above information, it can be inferred that when determining a specific age of acquisition, the type of analysis used can influence the results: if the total number of productions in the sample is considered or the number of subjects in the sample who produce a certain sound. Therefore, the variety of criteria used in research impacts the resulting ages in which their acquisition is presumed. This was observed in Torres et al. (2016) ${ }^{8}$, who analyzed a sample using different criteria for the methodological analysis, and observed differences of up to two years in the acquisition age of a given phoneme. Another explanation for the differences could be related to aspects of the research design, either the size of the sample, environmental aspects or instruments used, among others. Since there is no consensus on the criteria to be used, the information available to professionals is very diverse.

The age of acquisition of phonemes could also be related to the theoretical conception that Speech and Language Therapists have about phonological development in children. This conception of children's speech and language development may be influenced by either a phonetic or a phonological perspective. For example, when there is an error in a child's production, the cause is oriented either to a Phonological Processes of Simplification (PPS), derived from the Theory of Natural Phonology9,10, or towards Phonetic-Articulatory Adjustments ${ }^{11}$.

Along with this, different classifications of these speech sounds alterations are observed in the literature. Thus, in Spanish there are terms such as Speech Sounds Disorder (SSD), Speech and Articulation Disorder (SAD), Specific Speech Disorder, Phonological Disorder and the widely used term of Dyslalia ${ }^{12-15}$. In the Anglo-Saxon reference, the concept of Speech Sound Disorder (SSD) is widely used, which includes both articulatory and phonological difficulties ${ }^{16}$. The existence of different types of classification can generate confusion when diagnosing and/or intervening difficulties in children. The different nomenclatures refer to heterogeneous groups, which differ in the severity of the disorders, the underlying cause, the type of errors, the presence or absence of other linguistic difficulties, and the response to treatment ${ }^{16}$. In addition, previous studies have shown that there is no single way in which Speech and Language Therapists define articulatory and phonological disorders, nor consensus on the distinction between both terms ${ }^{17,18}$ which has a clear impact on clinical practice.

On the other hand, to investigate about the work and perception work of Speech and Language Therapists on different field-related topics seems to be relevant. An example of this can be found in the studies by Do Carmo Carvalho de Oliveira et al. $(2007)^{19}$ in the field of fluency; Sleifer, Américo Fernandes, $2011^{20}$ in cochlear implant and Vega, Torres, del Campo $(2017)^{21}$ on the role of Speech Therapists in the health sector, among others. Specifically referring to the field of Phonetics and Phonology, is the aforementioned study of Santana $(2010)^{18}$ in Brazil, Baker (2014) ${ }^{22}$ in Australia, Joffe and Pring (2008) ${ }^{23}$ in the United Kingdom; Priester, Post and Goorhuis-Brouwer (2009) ${ }^{17}$ in the Netherlands and Skahan, Watson and Lof (2007) ${ }^{24}$ in the USA.

In Chile, only a few studies have investigated the acquisition of phonemes in children, such as 
(Bermeosolo (2001) ${ }^{1}$; Vivar and León (2009) ${ }^{5}$ and Torres et al. $(2016)^{8}$, but none of these have focused on the perspective of the Speech and Language Therapists perception in their clinical work. The question arises, therefore, about what criteria are used regarding phonemes acquisition ages in our local area, given the disparity in the information that is available. Accordingly, this study proposes to explore the construction of these criteria, particularly those related to the phonemes $/ \mathrm{I} /, / \mathrm{r} /, / \mathrm{r} /$ in a group of Speech and Language Therapists in the Metropolitan Region. The objectives of this study are: (1) To describe the age at which Speech and Language Therapists consider that the phonemes $/ \mathrm{I} /, / \mathrm{r} / \mathrm{l} / \mathrm{r} /$ should be acquired. (2) To describe the criteria used by these Speech Therapists when considering a phoneme as acquired. (3) to inquire about the diagnostic criteria that Speech Therapists use to define the presence of an abnormal acquisition of phonemes.

\section{METHODS}

This research has been approved by the Human Research Ethics Committee of Universidad de Chile (Project No. 115-2015). All the Speech Therapists who participated approved their participation through an online Informed Consent.

\section{Design and sample}

An analytical cross-sectional study was carried out in which Speech and Language Therapists who practice professionally in the Metropolitan Region of Santiago, Chile, were invited to participate. Those who graduated from Chilean universities, and who worked in the clinical or educational field with children were selected. The inclusion criteria were: to be a registered Speech and Language Therapist from a Chilean university and to work in the clinical or educational field with children.

The sample consisted of 151 professionals. The mean age of the Speech and Language Therapists who answered the survey corresponded to 30.9 years ( \pm 6.14 ), with a minimum of 23 and a maximum of 60 years. $92.1 \%$ corresponded to the female sex, with an average work experience of 6.28 years ( \pm 5.56 ). $72.9 \%$ had postgraduate studies, with a Diploma being the most frequently reported option $(56.3 \%$ of the total sample). The work experience of the participants fluctuated between 1 and 33 years.

\section{Materials and procedures}

A survey was developed with two sections. In the first section, it was sought to describe the sample and determine compliance with the inclusion criteria. Participants were asked about age, university from which they obtained their undergraduate degree, completion of postgraduate studies and years of professional practice.

The second section of the instrument consisted of questions related to (1) age in which the professionals considered lateral and rhotic phonemes are acquired; (2) the criteria that these professionals use to consider a phoneme as acquired; and (3) diagnostic categories used by these professionals. All questions had the option to provide comments.

In this section, three questions related to the criteria that Speech and Language Therapists use to consider a phoneme as acquired were included; a question regarding the age at which lateral and rhotic phonemes are acquired and five questions aimed to clarify the concept the professional had regarding phonological and articulatory disorders. In the first case, they were asked about the linguistic units (isolated phoneme, syllables, words and spontaneous speech) that were considered; the way in which the professional evaluated the acquisition of the phoneme, and the use of quantitative criteria when determining acquisition (the child produces the phoneme at least one time, more than $50 \%$ of the time, they always produce it). In the second case, the participants were asked to select the age range in which the phoneme should be acquired. The possible answers ranged from 2.6-2.11 to 7.0-7.6 years. In the third aspect hypothetical cases were presented, in which the professional had to indicate if the described characteristics corresponded or not to an acquired phoneme, and to define if they were facing a dyslalia and/or a phonological disorder. Finally, the survey consulted about conceptual definitions for phonological and articulatory disorders. The term "Dyslalia" was used to refer to articulation problems, as it is probably the most broadly used and understood by the Speech and Language Therapists of the studied region.

The survey was administered through an online platform, which was disclosed through social networks for 4 months. Once said time elapsed, the platform was closed and the data obtained were analyzed. 


\section{Validity of the instrument}

A survey was created, which in its first version was submitted to the judgment of nine experts. This allowed to establish the validity of the content and the appearance of the survey, modifying the wording of the questions that were evaluated as "unclear". The new version, generated based on the comments of the experts, was applied in a pilot test to ten subjects that presented the same characteristics of the objective sample of the study.

\section{Data Analysis}

Because the answers to the questions in the instrument constitute nominal variables, proportions with $95 \%$ confidence intervals were estimated. In the case of analytical statistics, the proportions for each response were compared using a Fisher test, adjusted for multiple contrasts ("Bonferroni"). Due to the large number of possible contrasts between proportions (15 contrasts in case of having six response options and 21 with seven options), the results will be presented in the text, highlighting the most representative ones, together with their associated statistical significance values.

Multinomial models were constructed to determine the influence of years of experience on the probability of response in each multiple-choice question. To improve the accuracy of the estimates, the category that presented the largest sample was selected as reference. In the case of the questions in which two options were presented (dichotomous with yes or no answer), logistic regression models were created and the respective odds ratios (OR) were estimated.

Statistical programs STATA version 14 and $R$ version 3.3.3 were used. An alpha of $0.05 \%$ was considered.

\section{RESULTS}

\section{Age in which, according to the professionals and their clinical experience, lateral and rhotic phonemes are acquired}

There was variability in the age range in which, according to the interviewees, the phoneme / I / was acquired, fluctuating between "2.6 to 2.11 years" with $4.8 \%$ of the preferences, and " 5.0 to 5.6 years" with $1.4 \%$ (Table 1). The two categories with the highest response rate corresponded to " 3.6 to 3.11 " and " 4.0 to 4.6" with approximately $30 \%$ each. The two categories with the lowest proportion ("2.6 to 2.11" and "5.0 to 5.6 ") showed significant differences with respect to other categories (at least $p<0.05$ ).

In the case of the phoneme $/ \mathrm{r} /$, the age ranges selected by the interviewees fluctuated between "2.6 to 2.11 " and "6.0 to 6.6 ". In these extreme categories, preferences did not exceed 5\% (Table 1). The two ranges with the highest response rate corresponded to "4.6 to 4.11 " with about $40 \%$ and "4.0 to 4.6 " with $32 \%$. There were no significant differences between these last two ranges $(p=1.0)$. These were followed in preference by the category " 5.0 to 5.6 " with $21.6 \%$. There was also no difference between this last rank and the one that obtained more preferences $(p=0.07)$.

According to professionals, the / $\mathrm{r} /$ phoneme is preferably acquired between " 5.6 to 5.11 " with almost $40 \%$ of the answers (Table 1). The differences with respect to other response categories were statistically significant $(p<0.001)$. The categories " 5.0 to 5.6 " and " 6.0 to 6.6 " were the next options selected by the professionals. The remaining options reached values under $10 \%$.

Table 1. Answers to the question: "In the following question you will be presented with phonemes and you must indicate in which age range you consider that they should already be acquired"

\begin{tabular}{cccc}
\hline & Phoneme I & Phoneme r & Phoneme rr \\
\hline 2.6 to 2.11 & $4.08(1.83-8.87)$ & $0.68(0.09-4.74)$ & No observations \\
3.0 to 3.6 & $22.45(16.36-29.99)$ & $0.68(0.09-4.74)$ & $0.68(0.09-4.74)$ \\
3.6 to 3.11 & $28.57(21.78-36.49)$ & $2.03(0.65-6.17)$ & No observations \\
4.0 to 4.6 & $28.57(21.78-36.49)$ & $32.43(25.31-40.47)$ & $2.02(0.65-6.17)$ \\
4.6 to 4.11 & $14.97(10.01-21.78)$ & $38.51(30.94-46.68)$ & $9.46(5.65-15.42)$ \\
5.0 to 5.6 & $1.36(0.33-5.36)$ & $21.62(15.66-29.07)$ & $34.46(27.17-42.56)$ \\
5.6 to 5.11 & No observations & $2.70(1.01-7.05)$ & $39.87(32.22-48-05)$ \\
6.0 to 6.6 & No observations & $1.35(0.33-5.32)$ & $11.49(7.22-17.79)$ \\
6.6 to 6.11 & No observations & No observations & $2.2(0.65-6.17)$ \\
7.0 to 7.6 & No observations & No observations & No observations \\
\hline
\end{tabular}


The influence of work experience on the probability of response with respect to the age at which the phonemes $/ \mathrm{I} / \mathrm{,} / \mathrm{r} / \mathrm{,} / \mathrm{r} /$ are acquired is presented in figures 1,2 and 3 . There is a significant trend to select the response category " 5.0 to 5.6 " as the age of acquisition of the phoneme $/ 1 /$, as the work experience of the respondents increases. Figure 1 shows that for each year of increase in work experience, the probability of answering that the phoneme / 1 / is acquired at " 5.0 to 5.6 " years increases $18.24 \%(p<0,05)$. This, having as a reference category " 4.0 to 4.6 " years (category with the largest sample), which does not have a response preference in relation to the work experience of the professionals surveyed.

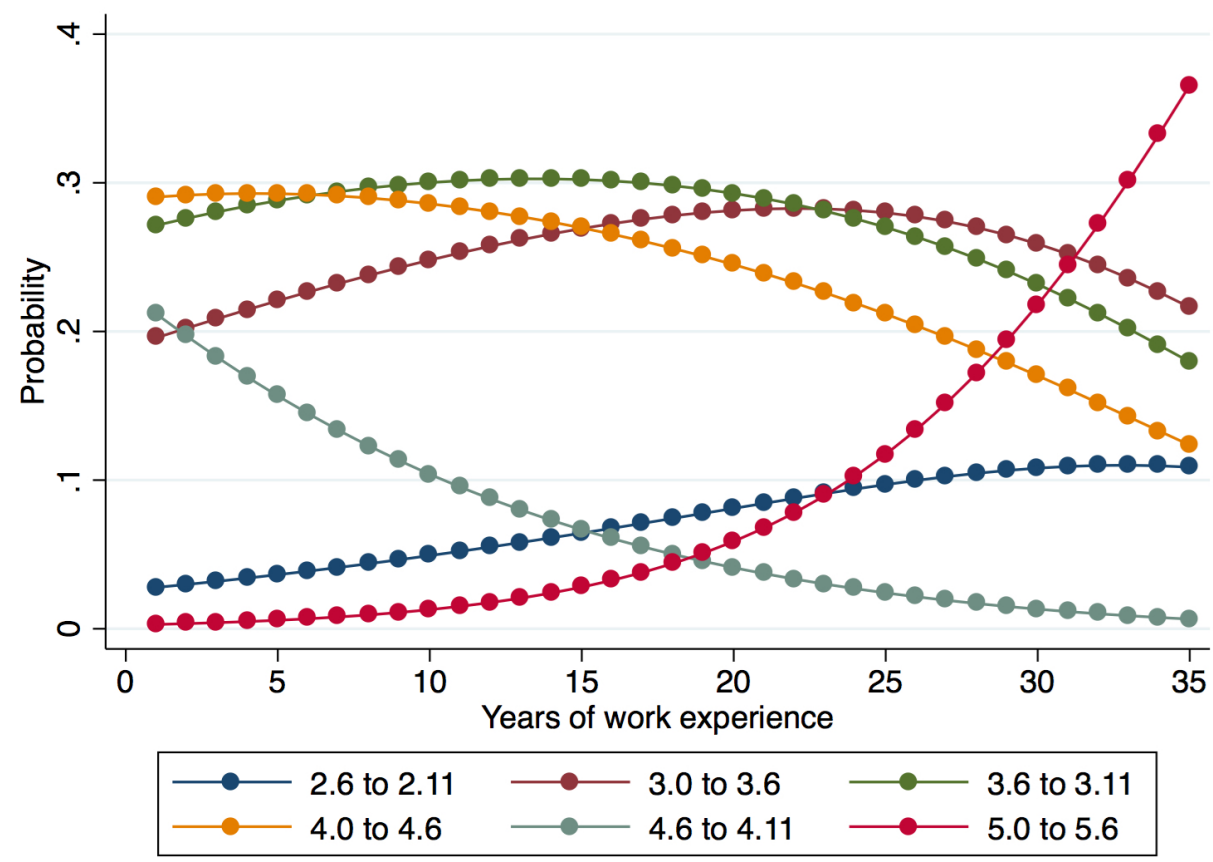

Figure 1. Work experience in relation to the probability of answer regarding the acquisition of phoneme / I/

There is a significant tendency to select the response category " 6.0 to 6.6 " as the age of acquisition of the phoneme $/ \mathrm{r} /$, as the work experience of the respondents increases. Figure 2 shows that for each year of increase in work experience, the probability of answering that the phoneme $/ \mathrm{r} /$ is acquired at " 6.0 to 6.6 " years is $16.82 \%$ higher $(p<0,05)$ in relation to the category " 4,6 to 4,11 " years (reference category with the largest sample). In turn, there is a $24.26 \%$ greater probability of selecting the category "6.0 to 6.6 " years in relation to " 5.0 to 5.6 " years $(p<0.05)$.
There is a significant tendency to select the response category "4.6 to 4.11 " as the age of acquisition of the phoneme $/ \mathrm{r} /$, as the work experience of the respondents increases. Figure 3 shows that for each year of increase in work experience, the probability of answering that the phoneme / $\mathrm{r} /$ is acquired at " 4,6 to 4,11 " years is $9.70 \%$ greater $(p<0,05)$ in relation to answering " 5.6 to 5.11 " years (reference category with the largest sample). 


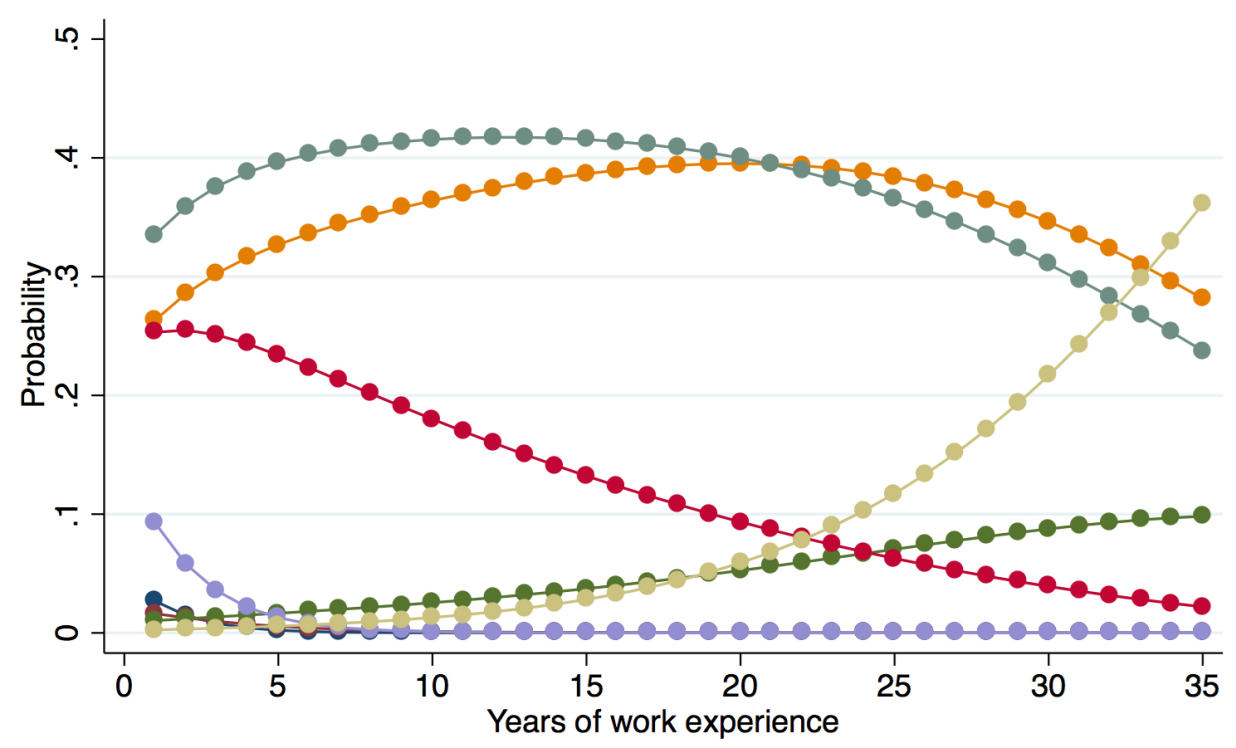

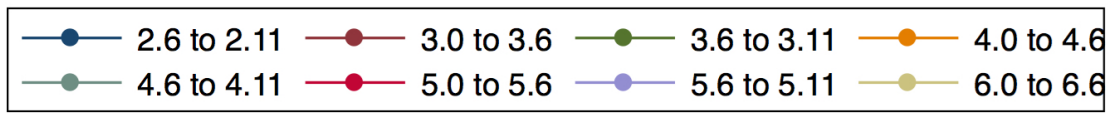

Figure 2. Work experience in relation to the probability of answer regarding the acquisition of phoneme /r/

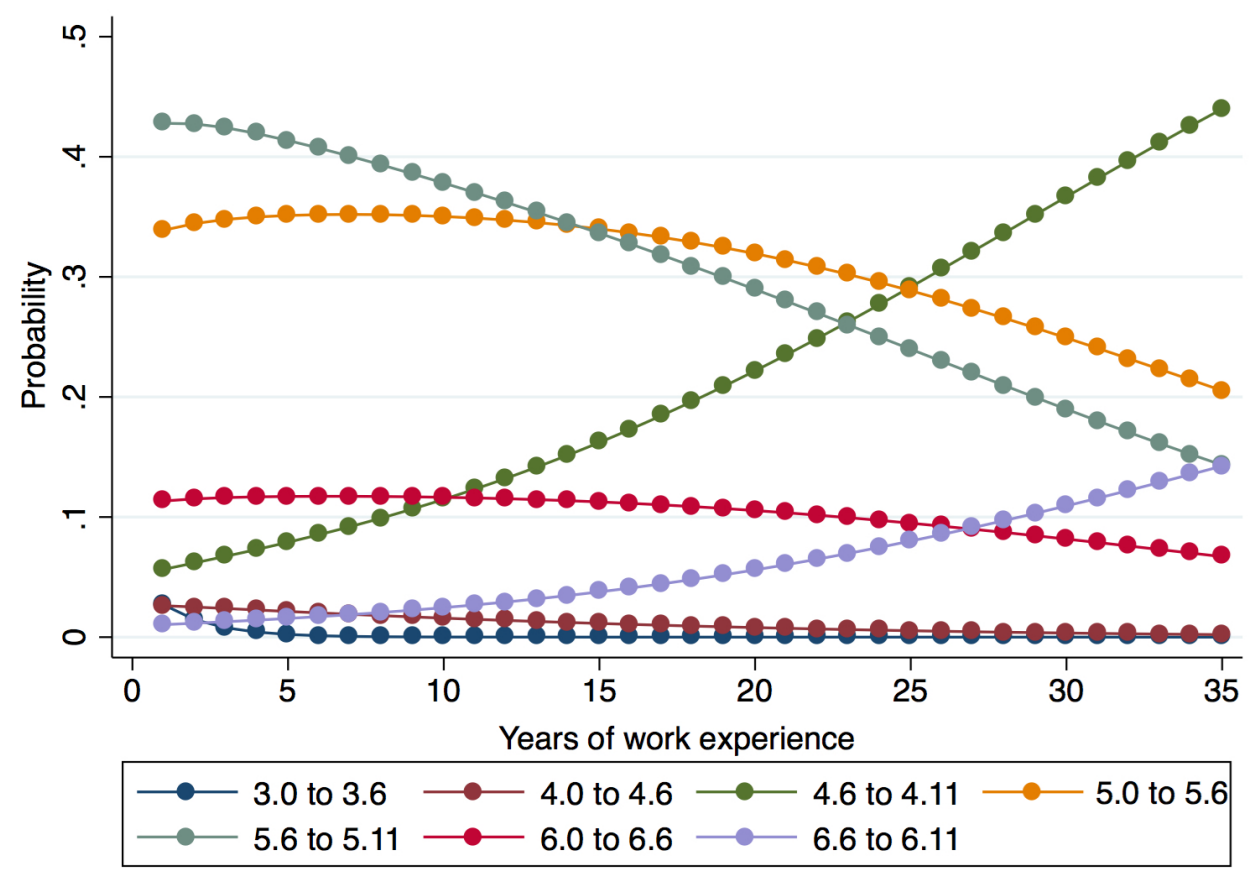

Figure 3. Work experience in relation to the probability of answer regarding the acquisition of phoneme / $\mathrm{r} /$ 


\section{Criteria used by Speech and Language Therapists to consider a phoneme as acquired}

In relation to the question about the presence of the phoneme in different linguistic units (Table 2), around $60 \%$ of the sample pointed out that a child already has acquired a phoneme when they produce it in all possible contexts, either as an isolated sound or in the context of syllables, words, sentences and spontaneous speech. This response alternative showed statistically significant differences with all the categories with which it was compared $(p<0.001)$. About $12 \%$ was inclined to the alternative "produces the phoneme in isolation and also in syllables (but not in words, sentences or spontaneous speech)". The remaining options reached values under 10\% (Table 2).

Table 2. Answers to the question: "In terms of presence of the phoneme in different linguistic units. you consider that a child has acquired a phoneme when:"

1. They present the phoneme only in isolation.

2. They present the phoneme in isolation and in syllables (but not in words. sentences or spontaneous speech).

3. They present the phoneme in isolation. in syllables and in words (but not in sentences).

4. They present the phoneme in isolation. in syllables. in words and in sentences.

5. They produce the phoneme in all the alternatives mentioned above. and also in spontaneous speech.

6. I preffer not to answer because I do not understand what this question reffers to.

7. I preffer not to answer because I ignore the information requested in this question.

\begin{tabular}{c}
$9.27(5.53-15.12)$ \\
$11.92(7.60-18.22)$ \\
$9.27(5.53-15.12)$ \\
$9.27(5.53-15.12)$ \\
$58.28(50.18-65.96)$ \\
$0.66(0.09-4.65)$ \\
$1.32(0.33-5.22)$ \\
\hline
\end{tabular}

$9.27(5.53-15.12)$

$1.92(7.60-18.22)$

$27(5.53-15.12)$

$0.66(0.09-4.65)$

Point values are displayed in \% and confidence interval to $95 \%$.

Just over half of the sample (53\%) indicated that at the time of the assessment of a child, they consider that they have acquired a phoneme when they produce it in spontaneous speech (Table 3). This alternative showed statistically significant differences with all the categories with which it was compared (at least $p<0.01$ ) with the exception of the other alternative with greater preference $(p=0.791)$. The latter corresponded to the option "Produces the phoneme in the direct repetition of words" $(40.40 \%)$, being followed by "Produces it only in repetition of syllables. Example: da, de, di, do, du, to know if they present the phoneme / d /" with $31.8 \%$; and "Produces the phoneme in word naming" with $30.5 \%$. The remaining options reached values under $30 \%$ (Table 3). Being a question with multiple choices, there were participants who answered one alternative (51.66\% Cl95\% 43.62-59.61), two alternatives (16.56\% $\mathrm{Cl} 95 \%$ 11.39-23.44), three alternatives ( $14.57 \%$ Cl95\% 9.74-21.22), four alternatives $(9.27 \% \mathrm{Cl} 95 \%$ 5.53-15.13), five alternatives (4.64\% Cl 95\% 2.21-9.48), and six alternatives (1.99 IC95\% 0.63-6.05).

Table 3. Answer to the question: "When evaluating a child. you consider that they have acquired a phoneme when"*

1. They present the phoneme only in isolation.

2. They produce it in syllable repetition. For example: da. de. di. do. du to know if they have the phoneme / d /.

3. They produce the phoneme in direct word repetition.

4. They produce the phoneme in deferred word repetition.

5. They produce the phoneme in word naming.

6. They produce the phoneme in spontaneous speech.

7. I preffer not to answer because I do not understand what this question reffers to.

8. I preffer not to answer because I ignore the information requested in this question.
$16.56(11.39-23.44)$

$31.79(24.79-39.72)$

$40.40(32.79-48.50)$

$27.81(21.19-35.58)$

$30.46(23.58-38.35)$

$52.98(44.92-60.89)$

No observations

$0.66(0.09-4.65)$

* Multiple choice question.

Point values are displayed in \% and confidence interval to $95 \%$. 
The most commonly reported quantitative criterion to determine whether a child has acquired a phoneme was to always produce the phoneme (46.3\%). This alternative showed statistically significant differences with all the categories with which it was compared (at least $p<0.05)$. About $30 \%$ was inclined to the option "Produces it more than $50 \%$ of the time" (Table 4).

Table 4. Answer to the question: "Do you use a quantitative criterion (that the child produces the phoneme one time. always or in a particular proportion) to determine whether a child has acquired a phoneme?"

\section{Lo dice al menos una vez \\ Lo dice más del $50 \%$ de las veces \\ Lo dice siempre \\ Prefiero no contestar porque no entiendo a qué se refiere esta pregunta \\ Diagnostic criteria used by these professionals to define the presence of a difficulty related to the acquisition of phonemes}

Prefiero no contestar porque desconozco la información que se consulta en esta pregunta
When asked about when they believed that a Dyslalia was present, both the option "The phoneme never appears and it is always replaced by the same sound except in clusters and coda position, because it is omitted instead of replaced with another" and "The phoneme never appears and it is always replaced with the same sound even in clusters and coda position" reached $35 \%$ (Table 5). Almost $20 \%$ of the interviewees selected the option "The phoneme never appears and the change is variable (with different phonemes)". This last option did not show significant differences with respect to the two most preferred ones ( $p=0.62$ ), while when contrasting it with other response alternatives it reached statistical significance $(p<0.001)$.

Table 5. Answer to the question: "You think there is the presence of a dyslalia when:"

1. The phoneme never appears and it is always replaced with the same sound except in clusters and codas where it is omitted instead of replaced.

$35.37(27.99-43.52)$

2. The phoneme never appears and it is always replaced with the same sound including in clusters and codas.

3. The phoneme never appears because it is always omitted. including clusters and codas.

4. The phoneme never appears and the replacement is varied (with different phonemes).

5. The phoneme appears only in some contexts (for example only in some positions. only in syllables or only in repetition but not in spontaneous speech).

6. The phoneme appears only in simple onset syllable but not in clusters or codas (when applicable).

7. There is no such thing as dyslalias.

8. I preffer not to answer because I do not understand what this question reffers to.

9. I preffer not to answer because I ignore the information requested in this question.
$35.37(27.99-43.52)$

$7.48(4.16-13.09)$

$19.73(14.01-27.04)$

No observations

$0.68(0.09-4.77)$

$1.36(0.33-5.36)$

No observations

No observations
In the question in which a clinical case was presented of a child who "never produces a phoneme and generally replaces it with the same phoneme, however, sometimes he replaces it with another phoneme", the interviewee had to indicate a possible diagnosis. Just under $35 \%$ indicated the coexistence of a Dyslalia and a Phonological Disorder. 33\% said that the case corresponded to Dyslalia and not to a Phonological Disorder, while around $30 \%$ preferred the option of Phonological Disorder and not Dyslalia (Table 6). There were no significant differences when contrasting the response options $(p=1.0)$. 
Table 6. Answer to the question: "In the case of a child who never produces a phoneme and in general replaces it with the same phoneme; however in some ocasions he changes it for a different phoneme. You would consider that the child presents:"

1. A phonological disorder and not a dyslalia.

2. A dyslalia and not a phonological disorder.

3. A dyslalia and a phonological disorder.

4. I preffer not to answer because I do not understand what this question reffers to.

5. I preffer not to answer because I ignore the information requested in this question.
$29.80(22.98-37.66)$

$33.11(26.00-41.09)$

$34.43(27.22-42.45)$

$1.32(0.33-5.22)$

$1.32(0.33-5.22)$

\section{DISCUSSION}

Age at which, according to the professionals and their clinical experience, lateral and rhotic phonemes are acquired.

According to the results obtained in this research, for the phoneme / I / there are 4 age categories that hold over $20 \%$ of the answers and among which the majority of Chilean Speech and Language Therapists (92\% approximately) are divided: these are 3.0 to $3.6 ; 3.6$ to $3.11 ; 4.0$ to 4.6 and 4.6 to 4.11 . The high dispersion of opinions regarding the same question is noteworthy. Something similar happens for the phoneme / $\mathrm{r} /$; opinions are divided mainly between 3 age ranges: 4.0 to $4.6 ; 4.6$ to 4.11 and 5.0 to 5.6 , with approximately $92 \%$ of the Speech Therapists who were consulted. Finally, in the case of the multiple vibrant phoneme, opinions are more limited, finding the majority of answers divided between two age categories: 5.0 to 5.6 and 5.6 to 5.11 years, reaching $74 \%$ of the speech therapists consulted.

It is possible that the variety found in the reference acquisition ages of the phonemes $/ \mathrm{l} /, / \mathrm{r} /, / \mathrm{r} /$ may be due to different methodological criteria used by Speech Therapists. For example, if a professional judges that the acquisition of a phoneme occurs when it is produced for the first time, they will consider an earlier reference age than a professional who thinks that the acquisition corresponds when there is a mastery of the phoneme in all contexts. It could also be hypothesized that it is possible that the different opinions are determined by the use of various bibliographic sources as reference, which in turn occupy different methodology and consequently obtain different results, as mentioned in Torres et $\mathrm{al}^{8}$. This would allow the existence of different criteria when deciding on a process of therapeutic intervention.

Regarding the question of whether work experience influences the age at which the professional considers the phonemes $/ \mathrm{l} /, / \mathrm{r} /, / \mathrm{r} /$ are acquired, it is noteworthy that a longer work experience is reflected in greater flexibility at the moment of judging the acquisition of phonemes $/ \mathrm{l} / \mathrm{,} / \mathrm{r} /$ but not in the case of phoneme / $\mathrm{r}$ 1. This could be explained by the apparent importance of this vibrant phoneme in the articulation development of a child. This fact could at the same time generate a high referral to the Speech and Language Therapist, due to the importance of this phoneme as a symbol of good articulation, which would take many educational establishments to set its acquisition as a requirement for admission. Finally, another probable explanation can be found among the limitations of the study, as the distribution of work experience length was not balanced and therefore it was not checked that the presence of professionals with different length of work experience was equivalent.

\section{Diagnostic criteria used by Speech and Language Therapists to consider a phoneme acquired}

Of the reported results, it is specially remarkable that apparently among Speech and Language Therapists of the Metropolitan Region of Chile there is a dichotomous "acquired-not acquired", more than a gradual acquisition point of view. This is clear given that about $47 \%$ of the sample considers a phoneme as "acquired" when a child always produces it (Table 2) and $58.28 \%$ mentions that to consider a phoneme as acquired in the evaluation, the subject must produce the phoneme in all possible contexts: in isolation, syllables, words, sentences and spontaneous speech (Table 2).

This dichotomous vision leaves behind the vision of a continuum in the acquisition of phonemes that is observed, for example, in Másdóttir and Stokes $(2015)^{25}$, who speak of "emergence, acquisition and mastery", indicating with these terms that a phoneme can be found in different stages of acquisition and not only in the "acquired / not acquired" stages (Torres et al., 2016) ${ }^{8}$. On the other hand Bosh, in the year $2003^{2}$, mentions that sounds are not acquired suddenly but gradually over time, with periods in which a phoneme is 
produced both correctly and incorrectly. The distinction between developing articulation and articulation difficulties has been observed in other studies such as that of Priester (2009) ${ }^{17}$.

\section{Diagnostic categories that the professionals use to define the presence of a difficulty related to the acquisition of phonemes}

Regarding the description of the concept of phonological and articulatory disorder that professionals have, based on the results it can be indicated that no consensus was found when diagnosing one or the other. Differences were found fundamentally in the type of error that each Speech Therapist considered characteristic of one or another diagnostic category. The aforementioned agrees with what was reported in Brazil by Santana et al. (2010) ${ }^{18}$, where the same phenomenon was identified among professionals. Based on this, some questions arise such as: Is this theoretical division applicable to the clinical reality? Are there limitations in the training of Speech and Language Therapists? Is the difficulty in applying a theoretical concept to clinical work? Regardless of the answers to these questions, the importance lies on the impact that this may have on the clinical work, since different diagnoses involve differences in the children's treatment, which in turn influences the chances of recovery, so the matter is not trivial.

On this point, as stated by Waring and Knight $(2013)^{16}$, we consider it fundamental that there is a unique and homogeneous classification system based on research, which presents clear and defined criteria and of course applies to professionals working in the clinic environment. This would facilitate the use of a common language that favors the intervention process.

\section{Projections of the study}

Characterizing the opinion and criteria of clinicians is a good research focus to advance in professional and theoretical terms. In this context, Kamhi $(1995)^{26}$, conducted a research review that links the perception of success of a treatment with the associated factors. He proposed a model of "expertise" in which 3 levels can be found. The first of the levels is the knowledge that the clinician has, the second deals with skills regarding procedures (evaluation, diagnosis, treatment) and solving problems and the third one is constituted by attitudes and interpersonal skills. When contrasting the findings of this research with the proposal by Kamhi, it can be stated that this study focused mainly on level 1 , but that it is necessary to plan an approach to more specific aspects of each of the levels he proposes. In particular, it is necessary to collect data referring to level 3 , on which no information was collected and which, according to the author, would be the one that impacts on the success of the treatment. Regarding level 2, other studies go deeper in the evaluation and treatment aspects, such as the ones carried out by Priester (2009) ${ }^{17}$ and Skahan (2007) ${ }^{24}$ for the first, and Joffe (2008) ${ }^{23}$ and Baker (2014) ${ }^{22}$ for the second. Both types of knowledge would be very interesting to approach and contrast in the local context.

On the other hand, the incidence of age, gender or socioeconomic status could influence phonetic development, just as these factors affect the reduction and elimination of phonological processes (Pavez, 2009) ${ }^{9}$.

\section{Limitations of the study}

As a limitation it is found that the convenience sample included only professionals from the Metropolitan Region of Santiago, preventing extrapolation of the results to the rest of the country. Despite this, it is a sample that allowed us to accurately describe the vast majority of the response categories in the survey. Although there were significant tendencies, there is inaccuracy when analyzing the relationship between work experience and the age at which professionals believe that lateral and rhotic phonemes are acquired. This is due to the smaller sample size of some categories of work experience length, which makes the total sample unbalanced regarding work experience. Further studies on the subject could address the aforementioned limitation.

\section{CONCLUSION}

A high variety of criteria is observed in the practice of Speech and Language Therapists of the Metropolitan Region of Chile regarding when to consider a phoneme as acquired; although a vision of "mastery" tends to prevail as an indicator of acquisition. The foregoing is relevant because of the influence that this has on the diagnosis of Speech and Language Disorders in children.

There is a high variety in the age range in which Speech Therapists expect lateral and rhotic phonemes to be found in children. In the case of the phoneme / I / most professionals expect it to be acquired between 3.0 years and 4.6 years; for the / r / between 4.0 and 
4.11 years and / $r /$ between 5.0 to 5.11. On the other hand, for the lateral and simple vibrant phonemes, the longer the work experience is, the greater the age at which these phonemes are expected to be present. The latter does not occur with the multiple vibrant phoneme.

Finally, there was no consensus among the specialists when characterizing the concepts of articulatory disorder and phonological disorder at the time of diagnosis.

\section{REFERENCES}

1. Bermeosolo J. Psicología del lenguaje. Santiago de Chile: Ediciones Universidad Católica de Chile; 2001.

2. Bosh L. Evaluación fonológica del habla infantil. Barcelona: Masson; 2004.

3. Dodd B, Holm A, Hua Z, Crisbie Sh. Phonological development: a normative study of British Englishspeaking children. Clinical Linguistics \& Phonetics. 2003;17(8):617-43.

4. Melgar M. Cómo detectar al niño con problemas del habla. 5a ed. Ciudad de México: Editorial Trillas; 2007.

5. Vivar $\mathrm{P}$, León $\mathrm{H}$. Desarrollo fonológico-fonético en un grupo de niños entre 3 y 5,11 años. Rev. CEFAC. 2009;11(2):190-8.

6. Bowen C. Children's speech sound disorders. $2^{\underline{a}}$ ed. Oxford: Wiley Blackwell; 2015.

7. Susanibar F, Dioses A, Castillo J. Evaluación de los trastornos de los sonidos del habla. En: Susanibar F, Dioses A, Marchesan I, Guzmán M, Leal G, Guitar B, Junqueira A (eds). Trastornos del habla de los fundamentos a la evaluación. Madrid:EOS; 2016. p. 125-93.

8. Torres F, Pino J, Peñaloza C, Rojas D, Fernández MA, Castro $P$ et al. Comparación de criterios para determinar la edad de adquisición de fonemas lateral y róticos. Rev Chil de Fono. 2016;15:1-16.

9. Pavez MM, Maggiolo M, Peñaloza C, Coloma CJ. Desarrollo fonológico en niños de 3 a 6 años: incidencia de la edad, el género y el nivel socioeconómico. RLA. 2009;47(2):89-109.

10. Pavez MM, Coloma CJ. Phonological problems in spanish-speaking children. En: Fernandes $F$ (org). Advances in Speech-language Pathology. Rijeka:In Tech; 2017. p. 55-75.

11. Torres-Bustos V, Soto-Barba J. Ajustes fonéticofonológicos en niños con trastornos específicos del lenguaje mixto (TEL Mixto). Onomázein. 2016;(33):69-87.
12. Organización Mundial de la Salud (OMS). Décima revisión de la clasificación internacional de las enfermedades. Trastornos mentales y del comportamiento. Descripción clínica y pautas para el diagnóstico. Madrid: Méditor; 1992.

13. Aguado G. Trastornos del habla y articulación. En: Coll-Florit M, Aguado G, Fernández-Zúñiga A, Gambra S, Perelló E, Vila-Rovira J (orgs). Trastornos del habla y de la voz. Barcelona:UOC; 2014. p. 13-61.

14. American Psychiatric Association (APA). Manual diagnóstico y estadístico de los trastornos mentales. 5a ed. Buenos Aires - Bogotá - Caracas - Madrid - México - Porto Alegre: Panamericana; 2014.

15. Susaníbar F, Dioses A, Tordera JC. Principios para la evaluación e intervención de los Trastornos de los Sonidos del Habla-TSH. En: Susaníbar F, Dioses A, Marchesan I, Guzmán M, Leal G, Guitar B et al (eds). Trastornos del habla de los fundamentos a la evaluación. Madrid: EOS; 2016. p. 47-124.

16. Waring $R$, Knight $R$. How should children with speech sound disorders be classified? A review and critical evaluation of current classification systems. Int J Lang Commun Disord. 2013;48(1):25-40.

17. Priester GH, Post WJ, Goorhuis-Brouwer SM. Problems in speech sound production in young children. An inventory study of the opinions of speech therapists. Int $\mathrm{J}$ Pediatr Otorhinolaryngol. 2009;73(8):1100-4.

18. Santana AP, de Almeida ML, da Rosa KS, de Souza M, Mendes J. O articulatório e o fonológico na clínica da linguagem: da teoria á prática. Rev. CEFAC. 2010;12(2):193-201.

19. Oliveira AMCC, Ribeiro IM, Merlo S, Chiappetta ALML. O que fonoaudiólogos e estudantes de fonoaudiologia entendem por fluência e disfluência. Rev. CEFAC. 2007;9(1):40-6.

20. Sleifer $P$, Fernandes VA. Conhecimento dos fonoaudiólogos de porto alegre sobre a atuação fonoaudiológica no implante coclear. Rev. CEFAC. 2011;13(2):259-70.

21. Vega YE, Torres AM, del Campo MN. Análisis del rol del fonoaudiólogo(a) en el sector salud en Chile. Ciencia y trabajo. 2017;59(19):76-80.

22. Baker E, McLeod SL. Speech-language pathologist' practices regarding assessment, analysis, target selection, intervention, and service delivery for children with speech sound disorders. Clin Linguist Phon. 2014;28(7-8):508-31. 
23. Joffe V, Ping T. Children with phonological problems: a survey of clinical practice. Int. J. Lang. Comm. Dis. 2008;43(2):154-64.

24. Skahan S, Watson M. Lof G. Speech-language pathologists' assessment practices for children with suspected speech sound disorders: results of a national survey. Am Journal Speech Lang Pathol. 2007;16(3):246-59.

25. Másdóttir T, Stokes S. Influence of consonant frequency on Icelandic-speaking children's speech acquisition. Int $\mathrm{J}$ Speech Lan Pathol. 2015;18(2):111-21.

26. Kamhi A. Research to practice. Defining, developing, and maintaining clinical expertis. Language, speech, and hearing services in schools. 1995;26(4):354-6. 